ALPHA N² 28 Julio 2009 (65-86)

ISSN 0716-4254

http://alpha.ulagos.cl

\title{
EL EXISTENCIALISMO FILOSÓFICO COMO PRAXIS LITERARIA EN LA OBRA DE RENATO RODRÍGUEZ
}

The existentialism philosophers praxis in the literary work by Renato Rodriguez

\author{
Álvaro Martín Navarro* \\ Existencia es lo que nunca es objeto; \\ es el origen a partir del cual yo pienso y actúo, \\ sobre el cual hablo en pensamientos \\ que no son conocimiento de algo: \\ "existencia" es lo que se refiere y relaciona \\ consigo mismo y, en ello, con su propia trascendencia. \\ Karl Jaspers
}

Resumen

El existencialismo ha sido presentado como opuesto a los sistemas filosóficos, insinuándolo como irracional, subjetivo y emocional. Y si bien la referencia a esta filosofía tiende a ser abarcada dentro del pensamiento europeo, pensamos que, a escala narrativa, hallamos "elementos existencialistas" en la literatura latinoamericana, incluyendo a la venezolana. Para tal fin analizaremos las obras del escritor venezolano Renato Rodríguez en las cuales nos enfrenta a la dinámica entre los sistemas de pensamiento filosófico como directriz de vida y la búsqueda de experiencias como conformadoras de la existencia humana.

Palabras clave: Filosofía, literatura, existencialismo, Renato Rodríguez.

\section{Abstract}

The existentialism appears as opposite to the tradicional philosophical systems and is insinuated as irrational, subjective and emotional. Although referentes to existentialism tend to be included within European thought, the researchers investigated, on a narrative scale, "existentialism elements" in Latin American literature, including Venezuela. For this aim, works of the Venezuelan writer Renato Rodríguez were analyzed, a writer whose works face us with the dynamics between systems of philosophical thought as directives for life, and the search for experiences such as confirmation of the human existence.

Key words: Philosophy, literature, existentialism, Renato Rodriguez. 
Álvaro Martín Navarro

\section{LOS MODOS DEL DISCURSO FILOSÓFICO EXISTENCIALISTA}

Dentro del ámbito filosófico, el término existencialismo lleva a pensar en autores como Kierkegaard, Nietzsche, Unamuno, Heidegger, Sartre; pero fuera del ámbito filosófico nos hace pensar en Dostoievski, Kafka, Musil. Como podemos apreciar, éstos son nombres que han confeccionado, dentro de la cultura occidental, una ansiedad profunda acerca del individuo y sus tensiones "racionales" con el entorno, con el otro, con lo indivisible. Cada uno de estos autores filosóficos (dentro de sus escrituras y estilos) buscó exponer su mirada con respecto a lo total, a lo general, a lo global del pensamiento, así como sus consideraciones sobre la herencia panlógica hegeliana, el evolucionismo positivista, el control marxista. Cada escritor existencialista (mencionado) buscó, a través de su obra, líneas de fuga donde las ideas derivadas de su individualidad tomaran legitimidad, criterio, validez, y especialmente su finitud ante lo absoluto, ${ }^{1}$ en otras palabras, dar preeminencia a la existencia sobre la esencia, a la filosofía que se ocupa del hombre, de relacionarse con la terca postura de preguntarse sobre los temas cotidianos, desdeñando inquirir por la physis, por el arjé, por lo tributario de las ideas.

Kierkegaard en Temor y temblor (1987) plantea uno de los problemas más complejos que pueda tener el individuo: su particularidad frente a lo absoluto. Para el escritor danés, las diversas respuestas que pueda dar un individuo frente a lo Absoluto resultan en una ristra de paradojas que hace que el individuo padezca diversas crisis producto del conflicto entre su interioridad y su exterioridad. Podemos entresacar del pensamiento de Kierkegaard que la realidad singular como existencia queda "fuera" de

\footnotetext{
${ }^{1}$ Castoriadis reflexiona en este punto dándonos los elementos que marcan la diferencia entre lo infinito del saber y la finitud del conocimiento. "Un problema subsiste, por cierto: siempre hay lo que llama Hegel, al principio de la Ciencia de la lógica, un espíritu finito ¿Por qué un espíritu finito? La empresa estaría a salvo si el espíritu finito pudiera reencontrar, en y por su finitud misma, la vía o una vía hacia el interior de esta exteriorización y, más aún, hacia la unidad de lo exterior y de lo interior, de la forma y del contenido; en resumidas cuentas, de todo aquello que nos encarnizamos en distinguir, en separar, en el pensamiento filosófico, y del cual Hegel tiende a mostrar constantemente que, aun siendo "contradictorio", se deja reconciliar, reunir, retomar en una totalidad superior. Hace falta, pues, que este espíritu finito pueda reencontrar, en y por su finitud misma, la vía hacia el interior de esta exteriorización, hacia la unidad de lo interior y de lo exterior, de la forma y del contenido, hacia el Saber absoluto. Es, como sabemos, el camino de la fenomenología, en donde el espíritu finito (la conciencia), comenzando por el aquí y ahora, desemboca en la idea de saber absoluto. El aquí y ahora es, evidentemente, el punto absoluto de la finitud. La fenomenología quiere mostrar que la finitud comprendiéndose a sí misma deja abolida, en el saber absoluto, su distinción del infinito” (2004:389-390).
} 
cualquier concepto que no coincida y se resista a ella. Por ejemplo, para un animal en particular, para una planta en particular, para un hombre en particular, la existencia es algo decisivo, pero el hombre particular no tiene una existencia genérica conceptual como sí la tendría la planta o el animal. De hecho, para una planta o un animal es más importante la especie que el individuo; para nosotros, el individuo no puede ser sacrificado a la especie. Kierkegaard piensa que la singularidad de nuestra existencia hace de ella un modo de ser fundamental para el hombre, y este modo de ser, al no poder ser reducido genérica o conceptualmente, sólo se puede expresar en el transcurrir de la existencia; ahora bien, en el transcurrir en la existencia los conceptos del individuo tienen como situación paralela la paradoja y sus posibles interrelaciones

Todavía puede formularse la paradoja diciendo que hay un deber absoluto hacia Dios, porque en ese deber el individuo se refiere como tal absolutamente a lo absoluto. En esas condiciones, cuando se dice que es un deber amar a Dios se expresa otra cosa que lo precedente, porque si este deber es absoluto, lo moral se halla rebajado a lo relativo. De todos modos no se sigue de ahí que la moral sea abolida, sino que recibe una expresión muy diferente, la de la paradoja, de suerte que por ejemplo el amor hacia Dios puede conducir al caballero de la fe a dar su amor al prójimo la expresión contraria de lo que desde el punto de vista moral es el deber (1987:100).

La paradoja que nace entre los individuos ante la representación de lo absoluto, busca volver lo absurdo al absoluto, ya que en la propia esencia de la palabra paradoja se halla su télos, $\pi \alpha \rho \alpha \delta$ o $\alpha \alpha$ (contra-opinión), algo que nos resulta increíble, bien porque está fragmentado, incompleto y, por lo tanto, a veces, se presenta como absurdo, y este télos quiebra la unidad del individuo, lo vuelve finito, por lo que pareciera que la única manera de vivir en el absoluto es en la anulación de las paradojas. Buscar contrasentidos ocultos, buscar los vacíos, pareciera que es la vía que denota al pensamiento la existencia en cuanto que ésta se muestra paradójica, incalculable, azarosa, absurda; de ahí que Camus plantee que toda reflexión² filosófica comienza frente al suicidio, frente al vacío, el vértigo, los laberintos, los sinsentidos, lo

\footnotetext{
2 "No hay más que un problema filosófico verdaderamente serio: el suicidio. Juzgar si la vida vale o no vale la pena vivirla es responder a la pregunta fundamental de la filosofía. Lo demás, si el mundo tiene tres dimensiones, si el espíritu tiene nueve o doce categorías, viene a continuación. Se trata de juegos; primeramente hay que responder. Y si es cierto, como pretende Nietzsche, que un filósofo, para ser estimable, debe predicar con el ejemplo, se advierte la importancia de esa respuesta, puesto que va a preceder al gesto definitivo” (Camus, 1995:15).
} 


\section{Álvaro Martín Navarro}

paradójico ¿Formas metafóricas para evitar o resistirse a conceptos reducidos de la existencia humana, correctos, absolutos? Si bien la paradoja se puede presentar como un método de desenmascaramiento por excelencia de lo absoluto, y la manera como se conforma, también se puede presentar como una orientadora de caminos, precisamente, el camino menos transitado, con menos señales, o curiosamente con muchas señales con direcciones contrapuestas - como el poste con múltiples direcciones y distancias que aparece en Mash (1970), película de Robert Altman, así como en su serie televisiva- y uno frente a este poste descubre el vértigo al vacío. Los caminos paradójicos apuntan a la derivación, a lo excéntrico; de hecho, podemos concebir el existencialismo como un pregón de caminos inexistentes - lo que conforma otra paradoja - si pensamos en mi existencia, y aceptamos que ésta no se halla derivada de nada, y que se legitima sola, podemos suponer que dentro de la existencia una escala ontológica se cierra sobre sí misma, quedando la existencia como un ser inmóvil y perfecto sobre sí, pero la existencia una vez que se legitima necesita hallar sus sentidos, los caminos, las trazas que la vayan construyendo, conformándola, individualizándola. Este camino, este "método" está alejado de la impronta del racionalismo cartesiano que se centra en el pensamiento, en formulaciones epistemológicas, en construcciones fundamentales del tipo "soy, luego existo", antes que sobre la existencia y las modulaciones que nos colocan en relación con el mundo. El concepto y sus esencialidades no son el fundamento de la existencia, sino que la existencia es el fundamento del concepto o, dentro de una expresión de Sartre, la existencia precede a la esencia y se expresa en un vivir en el mundo. ${ }^{3}$

El existencialismo podemos verlo como una metáfora de resistencia frente a las clasificaciones y conceptualizaciones del hombre y su hacer. Se presenta como un camino inexplorado que busca relacionarse con el mundo, evitando los sistemas panlógicos, así como al pensamiento positivista que marcó la vía del progreso, del éxito e, inclusive, podemos pensar el existencialismo como una resistencia a las vías marxistas, fenomenologistas gnoseológicas y las de la filosofía analítica que enmarcaron el pensamiento filosófico a principios del siglo XX. Un siglo fascinado por las llamadas ciencias objetivas, y donde algunos autores llegaron a reflexionar que el pensamiento filosófico no podría progresar si no adoptaba la metodología que

3 "Lo que complica las cosas es que hay dos especies de existencialistas: los primeros, que son cristianos, entre los cuales colocaría a Jaspers y a Gabriel Marcel, de confesión católica; y, por otra parte, los existencialistas ateos, entre los cuales hay que colocar a Heidegger, y también a los existencialistas franceses (y a mí mismo). Lo que tienen en común es simplemente que consideran que la existencia precede a la esencia o, si se prefiere, que hay que partir de la subjetividad” (Sartre, s/f):3). 
se inspira en las ciencias de la naturaleza — de ahí que aún se mantenga la carga semántica en las expresiones: ciencias sociales o ciencias humanasfrente a este reduccionismo científico, y frente a sistemas totalitarios y clasificatorios, el existencialismo reacciona al unísono, de manera paradójica y de manera frontal.

El hombre no es pura conciencia, no es un cogito absoluto y desencarnado como lo presentó Descartes, sino un sum cogitans, es decir, que uno como tal no es el pensar, porque el pensar es trascendencia de sí mismo, sino que, frente a Descartes, hay que afirmar que me pienso. El "yo pienso" cartesiano no es apertura de origen, sino obturador de cierre, el "me pienso" exige una confirmación de existencia y no un bautismo de la misma. Ni los conocimientos verificables, ni la absolutización de la conciencia, son fuentes de todo el sistema de la verdad y del ser. Más allá de la objetividad están las realidades existenciales que, como la libertad, la contingencia, la esperanza, el amor o la muerte no pueden encapsularse en la rigidez de conceptos. Por lo tanto, más que dominio de conceptos, curiosamente el existencialismo nos presenta la necesidad de transitar en el lenguaje. Si nos colocáramos en la mera teorética del existencialismo, nos ubicaríamos en sus clasificaciones, pero el existencialismo como proceso, como praxis, exigiría transitar el lenguaje sin más límites que el lenguaje mismo, abrirnos al juego del lenguaje - Sprachspiel- ya que, como explica Wittgenstein, en la Sprachspiel está "el todo constituido por el entrelazamiento del lenguaje con las acciones" (1998:7) implicando que el significado se constituye entonces como una forma de acción con la realidad y no como la sumisión de un lenguaje a una realidad externa y designada, a la manera de las teorías organizativas y/o clasificadoras; en otras palabras, el tránsito de la existencia dentro de una realidad construida con y desde el lenguaje, es lo que en el fondo permite el juego y el pensar existencialista, así como mostrar las paradojas que nos rodean.

Es así que el saber objetivo de pensamientos que consiste en poseer un determinado número de conocimientos sobre un objeto no comunica necesariamente las relaciones entre los objetos y su establecimiento, inscribiéndose así en el registro de lo problemático; y en esto radica la tradición del racionalismo: en que no tiene en cuenta suficientemente el mundo de lo concreto e identifica toda la realidad humana como objetos científicos; pero el mundo, más que estar catalogado por objetos, está circunscrito por lenguaje(s) y podríamos precisar que por juego(s) de lenguaje(s). Por eso el mundo de los pensamientos científicos es de tan abrumadora tristeza y cohesión, no hay camino ni tránsito y, por supuesto, no hay acción lúdica, paradojas y vértigos. El saber objetivo se mueve en las categorías del tener, del consolidar pero, en principio, lo que se tiene son las cosas $\mathrm{y}$, sin embargo, a medida que se 


\section{Álvaro Martín Navarro}

profundiza en el ser humano, la realidad se hace más compleja y, a la vez, menos accesible a la "comunicación objetiva”, porque el ser humano se afirma y se crea por el ejercicio mismo de un lenguaje, y sólo se puede realizar ese ejercicio en el tránsito de la vida, en el engranaje de la existencia de los otros en un quehacer lingüístico, con sus praxis al descubierto en una realidad lingüística.

Kierkegaard (1987) comienza una reflexión donde lo verdaderamente real es lo individual fundamentado en un lenguaje y su accionar praxístico ¿Dónde estoy? ¿Quién soy? ¿Quién me ha puesto aquí sin consultarme? ¿De qué me sirve encontrar una verdad objetiva si carece de significación para mi vida? Lo que yo necesito - anota en varias partes en su Diario de un seductor $(2007)^{4}$ y en las innumerables obras donde el lenguaje se sobrepone al individuo creando así una de las máximas paradojas - es ponerme en claro conmigo mismo, saber qué debo hacer. La cuestión entonces para Kierkegaard no es saber qué debo conocer, sino comprender mi destino, descubrir la verdad por la cual quiero vivir y morir. La subjetividad es la verdad o, dicho de otra manera, la verdad existe en el sujeto existente. ${ }^{5}$

Si pensamos que el existencialismo nace como respuesta a los sistemas panlógicos, nos hallamos entonces en la actualidad ante una modernidad que no da respuestas desde su razón objetiva, y entronizar la razón subjetiva, individual, particular, las causas de tal desplazamiento son múltiples. ${ }^{6} \mathrm{La}$ razón propia del existencialismo se entiende a sí misma irremisiblemente como "un mundo para sí", y si bien nosotros tuvimos que soportar en la contemporaneidad la pérdida de las ideas armónicas del individuo como espejo microcósmico del macrocosmo, la razón subjetiva distingue al menos

${ }^{4}$ El diario de un seductor ha sido editado como una obra particular, aunque pertenece a los diversos desarrollos teóricos que hace Kierkegaard entre el hombre ético y el hombre estético. Remitimos a la edición de Trotta titulada O lo uno o lo otro. Fragmento de vida I (2004).

${ }^{5}$ Queremos precisar que la noción de sujeto es altamente ambigua. Partimos de una imbricación a la idea que presenta Castoradis, cuando nos dice: "El sujeto: entiendo como tal otra cosa que lo simple psíquico. Lo simple psíquico es simplemente lo que pasa en nosotros; por ejemplo, ahí no se plantea —o solamente en el modo instrumental - la cuestión de la verdad ni tampoco la cuestión del bien y del mal. La única cuestión que se plantea ahí es la del placer, o de la conveniencia” (2004:55).

${ }^{6}$ Peter Sloterdijk, trata de mostrar la actitud cínica de la modernidad como resultado del mismo proceso de la ilustración y cómo ésta creó una "falsa conciencia ilustrada” que buscó medios panlógicos para explicar el mundo. "El cinismo es la falsa conciencia ilustrada. Es la conciencia modernizada y desgraciada, aquella en la que la ilustración ha trabajado al mismo tiempo con éxito y en vano. Ha aprendido su lección sobre la Ilustración, pero ni la ha consumado ni puede siquiera consumarla. En buena posición y miserable al mismo tiempo, esta conciencia ya no se siente afectada por ninguna otra crítica de la ideología, su falsedad está reflexivamente amortiguada” (2006:40). 
un microcaos dentro de un desorden inaccesible para los conceptos racionales. Pensamos que la razón subjetiva que guía al existencialismo en su transcurrir dentro del lenguaje por caminos que se relacionan con el mundo, se profundiza, porque no podemos creer, aunque quisiéramos, en un sentido de benevolencia de la totalidad o, dicho de otra manera, nos hemos subjetivado y vuelto existencialistas porque hemos experimentado la totalidad como desmembramiento, la naturaleza como fuente de crueles limitaciones y el mundo social como guerras mundiales Pensamos que esto ha despertado una perspicacia recelosa en nuestra conciencia moderna ante las doctrinas inoportunas de la totalidad, con las que se pretende presentar la miseria del mundo como una armonía y persuadir de que las pretensiones individuales de la vida generan un autosacrificio. Las teorías tradicionales sobre una razón objetiva, los sistemas filosóficos que soportan panlogismos, están comprometidos en el sentido de que se les ha desenmascarado como argucias al servicio de los ordenamientos del poder-saber — como constantemente lo refiere Foucault en sus múltiples ensayos como La verdad y las formas jurídicas o en los que confeccionan su libro Vigilar y castigar - una vez que la sospecha ha nacido, el individuo difícilmente se sacrificará “a sí mismo" o sacrificará "algo" de sí mismo por un poder-saber inaccesible. De ahí la perdida del patrón, ${ }^{7}$ el augurio de la caída, la entrada del "mal"; pero, como hemos indicado, éstas son paradojas que buscan presentarnos caminos que los sistemas filosóficos ya han censurado y clasificado, en su mayoría, como "errores".

\footnotetext{
${ }^{7}$ En La transparencia del mal, Baudrillard nos comenta como situaciones generadas de la modernidad, en las cuales a partir de un exceso de liberación todo quedó en una mera simulación en medio del vacío. No obstante, a la vez, este vacío está desbordado por la proliferación infinita de imágenes, realidades, ideas, conocimientos, obras artísticas, entre otros aspectos, que conllevan a una indiferencia total hacia el propio contenido y a una desvalorización. Según Baudrillard, el estado actual de las cosas es posterior a la orgía, donde todo ha sido liberado, o se han perdido los patrones, quedando el vacío, el cual es necesario mantener con los excesos de simulación de sueños, situaciones, imágenes, irrealidades y fantasías. Baudrillard propone unas categorías a partir del término "trans", que involucra todo sin la presencia de un campo diferencial: "la economía convertida en transeconomía, la estética convertida en transestética y el sexo convertido en transexual convergen conjuntamente en un proceso transversal y universal en el que ningún discurso podría ser ya la metáfora del otro, puesto que, para que exista metáfora, es preciso que existan unos campos diferenciales y unos objetos distintos. Ahora bien, la contaminación de todas las disciplinas acaba con esta posibilidad (1993:14). Pero, si bien Baudrillard y otros teóricos de la posmodernidad apuntan a los vacíos por pérdida de patrones, el existencialismo no vería en ello vacío o mal, sino chance, oportunidad de recorrer, de transitar para conformar sentidos, sin que necesariamente conglomeremos todo en nuevos catálogos, como lo propuesto por Baudrillard a través de sus “trans”, porque en el fondo mantiene la lógica de totalidad.
} 


\section{Álvaro Martín Navarro}

En una palabra, se pide a la filosofía no un sistema coherente de "verdades objetivas", sino que se haga humana, que descienda del empíreo de los principios y de las abstracciones para ocuparse de la vida del hombre, que es drama, soledad, desamparo, paradoja, subjetividad. Que podamos filosofar dentro de un existencialismo y pensarlo no como un no hacer discursos fantásticos a seres fantásticos, pues es a los existentes concretos a quienes hablamos ¿O debemos hablar?

Pero estos caminos “absurdos”, “paradójicos”, de "lenguajes”, tal y como se representan ante el pensamiento coherente y teleológico de los sistemas filosóficos, se presentan también junto al de libertad ¿Qué encontramos en estos caminos? No objetividad, control, sacrificio, sino libertad; no conocimiento, sino posibilidad de elección. Yo no tengo esencia, porque mi esencia es la libertad. "La libertad es el ser de la existencia — afirma Sartre en El existencialismo es humanismo - estamos solos, sin excusas, pero a la vez perdemos el todo, la unidad. ${ }^{8}$

Existir no es más que una activa y permanente elección. La vida se nos da, pero no se nos da hecha, de ahí la particularidad con las plantas y los animales. Es quehacer, tarea, faena diaria, gozo con el lenguaje, de modo que si el hombre no ejercita su libertad —errores, subjetividades, males- sin caer en la cosificación, se queda en un mero estar-ahí, y no en un ser-en-sí, aunque sabemos que estas mediaciones metafísicas rescatadas por Heidegger y profundizadas por Sartre implican una conciencia en el transitar o, en último término, la aplicabilidad de una moral y una ética; de aquí que el hombre, quiera o no, está forzado en cada instante a decidir lo que va a ser, significa que la vida es proyecto, o posibilidad, caminar y transitar sin caer en la antinomia de Sade. ${ }^{9}$ Ahora bien, este caminar, sostenido por una razón subjetiva, en el fondo modela una ética, para evitar que esta libertad sea aceptada como un "todo está permitido", o un abrirse a las pulsiones del gozo,

\footnotetext{
8 “A través de la libertad de los otros el mundo de fuera pierde su fiabilidad y su transparencia. Quien tiene conciencia de que es un ser libre, con capacidad de empezar siempre de nuevo y de saltar por encima de las consecuencias, de las normas y de la conducta previsible, sabe que también los otros pueden hacer lo mismo. Pero con ello, la transparencia desaparece del mundo" (Safranski, 2002:146).

${ }^{9}$ Para Safranski la antinomia de Sade es: "No podía escapar a la agudeza de Sade el que en la argumentación a favor del delito se aduce constantemente la naturaleza como una positiva magnitud de referencia. Si la naturaleza lo legitima todo, de pronto también el mal que se quiere cometer se convierte en una función de aquélla. Con lo cual el mal sigue siendo "bueno" para algo. O sea, también en los excesos se sirve todavía a ciertos fines de la naturaleza. En la cumbre del crimen, Sade quiere descubrir su libertad, y lo único que descubre es que continúa usando los andadores de la naturaleza. Al final estalla en un furor destructivo contra esta naturaleza” (2002:180).
} 
del placer, sin límites, de aquí la impronta ética que hará el existencialismo del siglo XX, cuidando los márgenes y colindando la libertad con la responsabilidad del vivir en la realidad sin sujetadores encauzados por una Naturaleza, bien sea derivada o sostenida, desde una Natura Naturata (primero causado), o de una Natura Naturans (causa primera).

Cada una de mis decisiones en el transitar es un comprometerse con uno mismo y el compromiso de mi opción tiene una repercusión social. Y, por otra parte, el precio del compromiso de la libertad deriva en la angustia, como bien lo demostró Kierkegaard en El concepto de la angustia (1979), al que podemos considerar como un sentimiento específico de la condición humana, ${ }^{10}$ el vértigo que se apodera del hombre ante el silencio del camino con múltiples señales. Sin embargo, para una especie de "existencialismo abierto", que evitaría ciertos nihilismos y especialmente ciertos silencios frente al otro, produciendo así una "conciencia” de que mi libertad se abre dentro de otras libertades, a la libertad del otro, porque la existencia es apertura, intersubjetividad, convivencia, relación con el mundo que desplaza cualquier ética prescriptiva. Para Sartre el otro es mi enemigo, el que con su mirada me vacía, me roba la libertad, es un usurpador y me esclaviza, hasta el punto de que el infierno son los otros. Para otros pensadores como Martín Buber, Mounier o Lévinas, el otro es un tú, una persona, una maravilla, alguien que está presente, que responde a mi llamada y con el que es posible mantener una relación de encuentros y que, a su vez, posibilita ciertas apuestas a una ética como las propuestas por Apel y Habermas. ${ }^{11} \mathrm{Y}$ en el encuentro la persona misma se me revela, me contacta con el mundo, y toda revelación implica un conocer del tránsito, del ir y del partir. Sólo en el encuentro con el otro la persona llega a ser persona y continúa siéndolo a lo largo de cualquier camino.

Todos estos elementos: el existencialismo como "irracionalidad", como me pienso, como libertad, como Sprachspiel, como enfrentamiento a los

\footnotetext{
10 “Analizando en El concepto de la angustia, este poder misterioso y terrible del renegar, Kierkegaard descubre en la misma primera aparición de aquél en la conciencia el crepúsculo de lo humano, el nacimiento del ego. El hombre nace a sí mismo como yo individual, saliendo de la inocencia originaria de la pura sensibilidad, cuando la revelación de la ley moral, trascendente y divina señala sus límites, arrojándolo al mismo tiempo a merced de la tentación de superarlos, de romper sus vínculos. La angustia o la "ansiedad" es ese sentimiento que impregna hasta el fondo de su sustanciar singular a todo hombre que se descubre como una individualidad “ante Dios” y siente que lo aferra por la garganta el vértigo de la propia infinita libertad de negarse y de ser él mismo 'como Dios'” (Prini, 1975:21).

${ }^{11}$ En "Ética analítica" Javier Sádaba, analiza los puntos referidos acerca de las propuestas de Habermans y Apel. Cfr. Historia de la ética, III. Victoria Camps (coordinadora) (2002).
} 


\section{Álvaro Martín Navarro}

sistemas filosóficos, presentándose como maneras particulares de experimentar y transitar en y con el mundo y trazando en juego(s) de lenguaje(s), las distintas actitudes frente al otro, y visiones sobre las paradojas, el mal y el errar, se pueden observar de manera diáfana en las obras del escritor venezolano Renato Rodríguez, quien más que pensar un existencialismo filosófico nos narra las modalidades de la existencia en el mundo y de algunas consecuencias.

\section{RENATO RODRÍGUEZ. LOS MODOS DEL DISCURSO LITERARIO}

Los inicios de R. Rodríguez como escritor son totalmente desconocidos. A diferencia de cualquier otro autor de la literatura venezolana, que es reseñado por toda la prensa, o comentado en los libros de bachillerato como ejemplos de escritura nacional y estudiados con profundidad en las universidades, Rodríguez ha sido totalmente clandestino. No ha sido catalogado - lo que nos permite hablar de él como filósofo o vagabundocuanto más le han dado existencia a su lenguaje como underground; para muchos de los pocos estudiosos de su obra, Rodríguez ha sido un topo, un escritor sui generis, un rebelde sin causa, o con causas poco conocidas. En fin, si tomamos un libro de bachillerato sobre literatura venezolana nos encontraremos con una abundante cantidad de nombres de escritores más o menos célebres, un orden, un absoluto que marcaron una época, unas ideas, un pensamiento ¿'Y Renato Rodríguez? No aparece, quizás, porque no quiso marcar época ni plasmar ideas o pensamientos. Asumió un transcurrir, un ir y regresar al lenguaje, una resistencia; experimentar juegos, pero lejos de las normas de la academia o para seducir a los intelectuales, como de una u otra manera lo recoge una supuesta frase atribuida a Joyce, quien había comentado que escribió el Ulises para tener entretenidos a los críticos durante cien años.

La mayoría de los estudios filosóficos buscan establecer al hombre en un saber profundo en relación con lo más abstracto, el pensar se queda en un refugio sin pretensiones y la vida, lo cotidiano, el día a día, se escapa y se pierde aunque es lo que lo constituye. La literatura implica necesariamente un compromiso con el vivir; de ahí que si bien un niño puede dominar un lenguaje abstracto como las matemáticas, y convertirse en un "genio", nunca hallaremos un niño "genio" en la literatura porque el lenguaje no es tan abstracto como las matemáticas e implica un existir, y esto evita la posibilidad de univocidad del significado, haciendo que la vida sea una excusa para perfeccionar una hermenéutica personal y a veces transferible como escritura. El lenguaje necesita transcurrir en relación con el mundo, de ahí que el existencialismo no sólo nos desvele ante la intemperie, sino que se desarrolle en la escritura. La literatura exige vida, vivencias, sensibilidad, reflexión, 
operaciones que necesitan tiempo, experiencias, viajes, y especialmente juego de lenguaje, juegos que a veces pueden prescindir del viaje, de las experiencias, de la sensibilidad, de la reflexión, pero un juego que se sabe juego y no un discurso que se asume como fundamento de la realidad, lo que conlleva al error, al mal, como frutos de la libertad y del pensarme.

Consideramos que el "me pienso" se presenta más accesible en la literatura, a través del "se piensa” del protagonista, y se aparta del "yo pienso" del discurso filosófico. A partir de esta idea podemos crear un eslabón para observar una propuesta de existencialismo filosófico como praxis literaria en la obra del escritor venezolano Renato Rodríguez. Si consideramos la escritura como un mero viajar y andar, su obra sería una autobiografía de peripecias, pero es en la autobiografía donde se funden por primera vez los problemas de la existencia; esto ha particularizado ciertas escrituras como las de san Agustín, Rousseau o el mismo Kierkegaard. Pero a diferencia de una mera autobiografía, la escritura existencialista cuestiona el sentido de este vivir en los contextos lógicos y de pensamiento de la época, porque me pienso. Podemos ver esto en las obras de Rodríguez. En principio sus libros muestran una secuencia de fotos, de archivos, de compromisos, de perplejidades vividas, pero también de problemas metafísicos, morales, éticos, políticos, sociales, educativos, etc., que redimensionan a una obra existencial desde una racionalidad subjetiva que está en límite entre el cinismo y el sarcasmo, alejándose de cualquier propuesta y quehacer filosófico.

Resultan admirables quienes han sido capaces de tomarse la creación narrativa como muestra de parodias de la existencia y, así, representar la existencia misma, como contrapartida de la formalidad y rigidez que han caracterizado a buena parte de nuestros escritores latinoamericanos - $-\mathrm{y}$, por supuesto, a la actitud de los escritores filosóficos- como algo que va más allá de lo acartonado si se trata de cautivar a los lectores. Y eso, precisamente, es lo que ha impactado de la narrativa y el discurso de Rodríguez: sus vinculaciones, no sólo con el estilo, sino con la existencia y el existencialismo.

Ya en su primera obra Al sur del equanil (1963), Rodríguez narra en primera persona las aventuras de un joven que quiere escribir —invitación hacia una Sprachspiel - pero que constantemente se ve impedido de totalizar, de lograr superaciones. Al entenderse o precisarse a través de un concepto como es el de escritor, se ve imposibilitado de conocerse. En algún momento pareciera que la novela se transforma en una parodia de un bildun gromans, en una novela de formación donde el protagonista busca formarse como escritor, como narrador, como generador de discursos, de pensamiento, de una identidad, e inclusive de un nombre. Para tal fin trata de hallar a Eduardo, su maestro - juego de metáforas en el proceso de creación, de transmisión de conocimientos entre maestro y discípulo- por diversas regiones del mundo. 


\section{Álvaro Martín Navarro}

Una búsqueda que conforma el eje de la obra, así como de las diversas reflexiones que se pueden obtener: escribir desde lo falso, desde la inexperiencia puede generar fracasos, pero pensar falsamente y vivir falsamente puede generar éxitos. Pensamos que en el fondo lo falso, el error, presenta el camino que por principio niegan los sistemas filosóficos. Rodríguez nos entrega una obra llena de surrealismo, de situaciones límites, de sin sentidos, de profundos desencantos metafísicos y, por supuesto, con elementos claves que participan en la lucha de un "destino marcado" como extensión de un pensar existencialista.

En Al sur del equanil observamos la inserción en una escritura existencialista en la que se despliegan los sentidos del viaje, el sentir, el cuestionamiento de la escritura, el maestro, los sistemas, la razón y la fe; pero también se introduce con acierto el humor, que hace ver lo cotidiano y sus paradojas y, por ende, realiza una actividad crítica que nos prepara a ver el Mal, el Error y lo Feo. En los orígenes de la escritura alternativa a la filosófica, como es el caso de la comedia ática, ésta poseía como motor eficiente al humor, característica que culturalmente ha sido cuestionada por las instituciones que se soportan sobre pensamientos y escritos serios y fuertes, porque, básicamente, la escritura humorística permite la asimilación "natural” de lo mejor a lo peor, de lo imposible y de la violación de las leyes de la naturaleza, de la desvalorización de la autoridad, de las costumbres y de las instituciones, de la selección de las cosas menos dignas, de la aceptación de lo equívoco entre palabras similares para cosas distintas y, por supuesto, el uso de palabras distintas para cosas similares, de los errores de pronunciación. En fin, una lista que - a primera vista - cualquier academia, institución de poder o sistema filosófico condena abiertamente; de ahí que el humor podamos pensarlo como un elemento existencial, un momento donde nos descubrimos corporalmente frente a las paradojas y los absurdos del mundo que se insertan y nacen en la escritura literaria.

Por eso la comedia, el humor y sus variantes — como la ironía, el sarcasmo y la sátira - han sido marginados de los procesos de "desarrollo" de la cultura; pero lo interesante y paradójico es que la risa, así como el humor, es tan "propia" del hombre que nunca se ha podido controlar ni extinguir, permaneciendo como una línea paralela de su existir y, en este sentido, como posibilidad en la construcción de una modulación de la subjetividad.

No podemos negar que Renato Rodríguez es un maestro del humor; y uno de los primeros frutos de un pensar existencialista, sin duda, debe ser el humor. Las preguntas constantes acerca de los órdenes de la realidad, su control, son ridiculizados en nuestro transitar en el mundo, mostrándonos lo frágil de los pensamientos absolutos y de la fe en los alcances epistemológicos. 
El bonche (1976) y La noche escuece (1985) son dos monumentos para asimilar las condiciones del hombre venezolano en sus cambios culturales, económicos y afectivos y su transitar en el mundo. El bonche es un título que ya nos invita a pensar con un mínimo de seriedad lo que puede contener la obra, porque ¿De qué se puede tratar una novela llamada El bonche? En la primera edición (Monte Ávila, 1976) en su primera página aparece el dibujo de unos gatos gritando, bochinche puro bochinche. Lo que no se imagina el lector es que la obra trata de las tragicomedias de un bananero - término que se le daba a los latinoamericanos en los años sesenta en los Estados Unidosa quien en su andar por las grandes metrópolis de la nación del norte le nacen desgarramientos de su visión del mundo que choca con una concepción homogénea y concreta de la vida. A la vez, se narran las andanzas de artistas, bohemios y escritores latinoamericanos y, por supuesto, del personaje principal, don José Rodríguez del Campo y Verde, noble hidalgo margariteño quien viaja y trabaja mostrando lo limitado y lo torpe de las culturas y sus actuantes. El bonche comienza como un contrapunteo filosófico, luego de mostrar la caricatura de los gatos bonchando

Por supuesto que cuando en los bonches le preguntan a uno “¿Qué haces tú?" Uno no puede ser tan pendejo como para decir "YO PIENSO”. ¡Qué diablos! ¡Todo el mundo piensa! ¿No? SUM ERGO COGITO ¡Qué bella frase! Esto es lo bueno del Latín, que aunque sea griego para mí puedo usarlo porque seguro que es chino para los demás y en cualquier caso, la belleza de las frases en Latín se impone a mi ignorancia y a la de los demás. Como dicen allá en Margarita Island INTELLECTUS APRETATUS DISCURRIT. A menudo pienso en todas estas cosas y a menudo hallo respuestas, pero una cosa que siempre me deja en duda es preguntarme -cómo lo hago casi a diarioque para qué está uno en el mundo o si, por acaso, está en el mundo para algo ¿Para pensar tal vez? Nooo... Pensar es lo que jode todo. Uno piensa en la felicidad y ya no puede ser feliz, piensa en el sexo y se vuelve impotente, no, no... Se vuelve uno metafísico y esto no puede ser ¡ $\mathrm{Si}$ uno es físico! No hay respuesta razonable. ${ }^{12}$

Rodríguez asume la escritura como archivos de vida de las diversas preguntas en las que busca sentido su pensar en relación con el vivir y la cotidianeidad, se piensa como reflejo de un "me pienso" y así, no acepta una vida preestablecida, la escritura no debe dejarse llevar por una idea o ideas - tópico propio de los sistemas filosóficos - sino por las diversas vivencias

${ }^{12}$ Renato Rodríguez. El bonche. Caracas: Monte Ávila, 1976, 11. Citaremos por esta edición. 


\section{Álvaro Martín Navarro}

como nos lo muestra en la cita anterior: que el hombre puede generar los adornos, las contrariedades, lo inverosímil que le puede ocurrir.

Si El bonche nos recuerda lo picaresco que heredamos de la visión española de la búsqueda de identidad, de sentido, de camino, pensamos que en La noche escuece (1985), Rodríguez realiza un giro al respecto porque ya no será un "bananero" hidalgo margariteño buscando anclar y entender lo distinto a sí, sino que son las aventuras y especialmente las reflexiones de un venezolano que realiza su odisea por su país, comenzando por La Guaira y finalizando en una isla desierta.

En La noche escuece, el protagonista narra las mil y una aventuras diarias que le ocurren por su ingenuidad a un personaje anónimo —en el sentido de que toda la obra se narra en primera persona y nunca nombran al narrador - que se piensa entre paradojas

Yo fui el único entre los estudiantes que ingresaron ese año a la Universidad que presentó al inscribirse un certificado médico legítimo, legalmente expedido y con todos los sellos y firmas que hacían falta. La noticia se esparció dentro de la comunidad universitaria y cada vez que llegaba a conocer a alguien, profesor, estudiante o empleado, escuchaba siempre la misma ominosa frase: "así que usted es el hombre de la levita gris”. Y era que en mi inocencia de siempre no sabía ni podía imaginarlo que por la módica suma de diez bolívares uno podía entrar a algún consultorio médico y salir con su certificado en el bolsillo sin ser siquiera examinado. ${ }^{13}$

Se trata de una "ingenuidad" que caracterizará al protagonista pero que pensamos es la representación de la ruptura de una Venezuela premoderna, guiada por el positivismo, hacia una Venezuela moderna, cínica, individualista, subjetiva, sin que haya mediado el tiempo suficiente para asimilar los cambios que comienzan a inundar el país a través de las industrias, de la economía, de las perspectivas de éxito y progreso. La velocidad, lo inmediato, el estigma derivado de los trabajos agrarios de una Venezuela rural y sus transformaciones por la facilidad de hacer dinero con economías endebles, la corrupción, así como las diversas relaciones que se establecen entre los individuos y sus sueños, son los temas que subrepticiamente Renato Rodríguez muestra en esta obra.

Pero la obra no consiste sólo en una mera crítica a la modernidad y el devenir histórico cultural de Venezuela. El protagonista parte a la búsqueda

\footnotetext{
${ }^{13}$ Renato Rodríguez. La noche escuece. Caracas: Libros RARos, 1985, 19. Citaremos por esta edición.
} 
de un sentido de la vida con base en el trabajo, a través de los elementos que da el pensar positivo, la ética laboral. Dentro de la cultura occidental, el trabajo no sólo se ha presentado como un medio de supervivencia, sino como un valor moral, curiosamente como un sistema de pensamiento. Trabajar indica un sentido de las cosas, una rutina, un establecer futuro, responsabilidad, alternativas de desarrollo y crecimiento. Renato Rodríguez ya no presenta al incipiente escritor que busca los consejos de su maestro para darse sentido como escritor en $\mathrm{Al}$ sur del equanil, ni muestra los múltiples choques culturales y diversas weltangschauung de un trotamundo por Norteamérica y Europa, como en El bonche. Ahora, en La noche escuece desvela las contradicciones del pensar venezolano, las distintas visiones y pensamientos $\mathrm{u}$ órdenes del mundo que hemos heredado, y la necesidad de individualmente de darse sentido; vivencia de buscar un tránsito dentro de un mundo que de una u otra manera está definido, así como hacer —en praxis del lenguaje — una praxis en la existencia.

El protagonista de La noche escuece logra realizar trabajo(s) dentro del desarrollo de la modernidad venezolana como la de ser testigo, agricultor, asistente de mago, asesor de empresa fantasma, distribuidor de cervezas, pero también nos revela profesiones como la de falsificador de títulos universitarios, la de poeta, el ladrón culto, el chulo, el torero y toda una serie de ocupaciones que nos exigen nuevas formas de entender la realidad y vincularse con ella de una manera empírica, de una manera no lineal derivada de un pensamiento moderno. El problema no es la duda metódica, sino el hacer no como pérdida, sino como consolidación de saber y pensar.

En esta novela, Rodríguez busca dar explicaciones a nuevas realidades que se plantearon durante el período de modernización, en la cima de un pensamiento positivista, mediante conceptos como progreso, orden, futuro. El protagonista transita Venezuela y, sutilmente, nos cuenta la historia contemporánea de esta nación entre los años cincuenta y sesenta, con todo y el derrocamiento de Pérez Jiménez oído a través de la radio en un auto mientras viajaba por el país, y mostrando las diversas actitudes que las personas desplegaban ante el hecho del derrocamiento. En esta tercera novela, Rodríguez cuenta historias de gente alegre y triste ante el acontecer del país; la de aquellos que admiran lo nuevo y la de otros que demuestran nostalgias por lo que se pierde pero, quizás, lo más trágico sea la visión que hace con respecto a la vinculación entre el trabajo, el dinero, la satisfacción, el orden y el progreso, y cómo este conjunto de ideas “corrompen” la posibilidad de un país moderno a partir del valor y de la riqueza del trabajo, mostrando la paradoja y la incoherencia de un pensar positivista que ahogó el pensar académico en Venezuela. 


\section{Álvaro Martín Navarro}

Quizás una de las escenas más impresionantes de la obra - $-\mathrm{y}$ que puede sintetizar parte de esta reflexión y propuesta existencialista que hace idea del encuentro fenomenológico con las cosas sin orden, sin presupuestos, desunídando la percepción- ${ }^{14}$ es cuando el personaje se dedica al agro, mostrándonos así la sencillez de la vida y sus satisfacciones por el buen trabajo, por la producción de hortalizas y, posteriormente de leche, pero también indica cómo el personaje comienza a tener aspiraciones de ser empresario, de pasar de agricultor a ganadero, a posible productor de carne vacuna y porcina. De hecho busca ramificar sus producciones. Así, una tarde hablando con un productor porcino, le explica sus ganas de expansión y teniendo al productor porcino de origen italiano como modelo de un hombre exitoso (y a quien se presenta como metáfora de sujeto racional), el protagonista le pide consejo, descubriendo que la modernidad contiene la desesperanza dentro de sí

Turiddu se detuvo a pensar cuando le hablé de mi proyecto de criar cerdos y después de reflexionar un poco me dio con toda franqueza su opinión "Si de oñi modo tú quiere los cochinos — dijo— están a la

\footnotetext{
${ }^{14}$ En La náusea podemos hallar estos elementos cuando Roquentin se enfrenta, en su obsesión, con el hecho de existir e intenta atrapar a los evasivos sentidos: "Bueno, hace un rato estaba yo en el jardín público. La raíz del castaño se hundía en la tierra, justo debajo de mi banco. Yo ya no recordaba que era una raíz. Las palabras se habían desvanecido, y con ellas la significación de las cosas, sus modos de empleo, las débiles marcas que los hombres han trazado en su superficie. Estaba sentado, un poco encorvado, baja la cabeza, solo frente a aquella masa negra y nudosa, enteramente bruta y que me daba miedo. Y entonces tuve esa iluminación. Me cortó el aliento. Jamás había presentido, antes de estos últimos días, lo que quería decir “existir”. Era como los demás, como los que se pasean a la orilla del mar con sus trajes de primavera. Decía como ellos: "el mar es verde”, "aquel punto blanco, allá arriba, es una gaviota”, pero no sentía que aquello existía, que la gaviota era una "gaviota-existente"; de ordinario la existencia se oculta. Está ahí, alrededor de nosotros, en nosotros, ella es nosotros, no es posible decir dos palabras sin hablar de ella y, finalmente, queda intocada. Hay que convencerse de que, cuando creía pensar en ella, no pensaba en nada, tenía la cabeza vacía o más exactamente una palabra en la cabeza, la palabra "ser”. O pensaba... ¿Cómo decirlo? Pensaba la pertenencia, me decía que el mar pertenecía a la clase de los objetos verdes o que el verde formaba parte de las cualidades del mar. Aun mirando las cosas, estaba a cien leguas de pensar que existían: se me presentaban como un decorado. Las tomaba en mis manos, me servían como instrumentos, preveía sus resistencias. Pero todo esto pasaba en la superficie. Si me hubieran preguntado qué era la existencia, habría respondido de buena fe que no era nada, exactamente una forma vacía que se agrega a las cosas desde afuera, sin modificar su naturaleza. Y de golpe estaba allí, clara como el día: la existencia se descubrió de improviso. Había perdido su apariencia inofensiva de categoría abstracta; era la materia misma de las cosas, aquella raíz estaba amasada en existencia. O más bien la raíz, las verjas del jardín, el césped ralo, todo se había desvanecido; la diversidad de las cosas, su individualidad sólo eran una apariencia, un barniz. Ese barniz se había fundido, quedaban masas monstruosas y blandas, en desorden, desnudas, con una desnudez espantosa y obscena” (Sartre, 1988:101).
} 
órdine. Te llevas los cochinos e poi me pagas cuando vuoi. Ma, donde tú estai non ti resulta. Tengo la esperienza, l’o fato per muchi añi, si non si puo conseguire regalato cuelo que manyano o cuasi tuto, non ti resulta. Digamos que se puo conseguire per il costo del transporte. Como cui a Maracay. Los cochinos manyano troppo. Cui a Maracay sí; se consigue gratis la sobra del ristorante, il recorte de la pasta da'l pastificho, la leche” — ¡la qué...! —exclamé asombrado— ¿Dónde vas a conseguir leche gratis? Vamos Turiddu, tú como que me estás tomando el pelo - Cui, a Maracay, dijo - si vede que non mi credi. Mete il camione pa'dentro y vente con me, ti hago vedere'na cosa... Fuimos Turiddu y yo en la camioneta hasta el Lactario de Maracay. Al llegar le dio un billete de a diez bolívares al portero de la entrada posterior y entramos; después de hacer una cola ya que había otros vehículos esperando allí su turno, Turiddu se hizo llenar de leche los seis tambores de a doscientos litros cada uno que llevaba en la camioneta. Cuando vi aquello me quedé más que perplejo, me quedé pendejo. Turiddu se llevaba por diez bolívares y el trabajo de ir a recogerla una cantidad de leche igual a la que después de tantos sacrificios, esfuerzos y dedicación mi finca había llegado a producir en una semana —si nosotros non la agarramo, la bótano a la cloaca-, dijo Turiddu ya en marcha hacia su granja, Cuindichi mila litri todos los días. Le sácano un po’di crema para hacer el burro ¿Como si llama? Ah, sí, la mantequilla, e poi la bótano. Todo se perderebe si noi non la agarramo. In Italia — continuó- si cualque d'uno fa'na cosa cosí lo fuchílano. Pum pum pum. ¡Lo amazzano, caro mío, lo amazzano! —Sí acerté a decir abriendo la boca por primera vez desde que había visto aquel caudal de leche- es ni más ni menos que una barbaridad, un verdadero crimen. La depresión que comencé a sentir me dejó sin hablar, casi no me despedí de Turiddu (1985:108-109).

Entre la ingenuidad y el despertar ante una realidad, el personaje de $L a$ noche escuece busca explicar, hallar sentido(s), conseguir futuro, el concepto de razón, esperanza, orden, progreso, se desvanece sin sentido, como Antoine Roquentin de La náusea de Sartre. Así, esta novela no sólo recoge lo previamente trabajado por Rodríguez, las situaciones absurdas, el humor, la búsqueda de sentidos y el sentimiento de fracaso ante los órdenes del pensamiento, elementos propios del existencialismo, sino que se constituye como una de las pocas novelas venezolanas que tiene estos elementos y que, a su vez, critica la construcción de la modernidad en Venezuela; que critica lo estúpido de los individuos que optan por la comodidad y el trabajo sin moral y el esfuerzo sin ética. En síntesis, un eje del trabajo en el cual el individuo, en el fondo, no se siente bien consigo mismo. Estas diversas situaciones que narra Rodríguez hacen que se plantee esta realidad moderna desde diversas 


\section{Álvaro Martín Navarro}

perspectivas, pero no desde un apostolado de la nostalgia, como hacen algunos escritores contemporáneos, ${ }^{15}$ sino desde la metodología del humor como modo de introducir y criticar la realidad con una sonrisa y un transitar por el mundo que, a su vez, ensaya un método fenomenológico.

Pero este transitar por el mundo no pretenderá una desaparición del escritor, del bohemio, del decepcionado, sino que mantiene un diálogo con el discurso filosófico, con el pensamiento. La noche escuece presenta, también, a Aurelio, un personaje filosófico, que genera un discurso institucional que se vincula con la "seriedad" de la filosofía: "No todos los esgrimistas eran estudiantes de Ingeniería; Aurelio por ejemplo, lo era de Filosofía y Letras" (57). Aurelio se transformará en amigo a distancia del personaje principal, que se piensa, que estará a lo largo de la obra. Curiosamente, dicha amistad nace a partir de una serie de reflexiones sobre el humor, la risa, lo absurdo del mundo y el existencialismo. De hecho, Aurelio toma la meditación que hace Albert Camus sobre que el único problema serio de la filosofía es el suicidio como punto de honor de sus pensamientos.

El existencialismo — que se "opone” a una metafísica de la coherencia interna propia de la filosofía que se afianza en las armas de la racionalidad del pensamiento moderno - se presenta, por lo tanto, como irracional ante los campos ordenados del saber positivo, científico o histórico. También implica una confusión de las categorías, formas o valores del espíritu dentro de las incontrolables afirmaciones de lo vital, y un replanteamiento de problemas (el mal, la opción, el pecado, la muerte, la trascendencia) que, en el fondo, son modos de críticas. Pero la actitud "existencialista” de Aurelio, y las maneras como éste la quiere replantear en la Filosofía, ya no encuentra modos de crítica sino salidas que se presentan en las propuestas mordaces a la resolución de problema(s) desde el puro hedonismo de un saber. Las críticas de Aurelio ponen de relieve lo opaco de las experiencias para pensar y las trae a colación en cada uno de sus discursos, en su existencialismo sin praxis y donde la esencia subsume la existencia.

Luego de haber viajado por parte de Venezuela, el protagonista tiene una última conversación con Aurelio, la que se inicia con las faustas obras de filosofía que, tiempo atrás, ambos habían comentado

\footnotetext{
15 Podríamos hablar de escritores con el apostolado de la nostalgia. Serían aquellos que desarrollan obras que se estrechan con la historia y buscan en ella personajes y hechos para recrear visiones contemporáneas, filosóficas y estéticas. En Venezuela podemos ver estos estilos en Ana Teresa Torres (Doña Inés contra el olvido), Inés Quintero (El último Marqués) y Federico Vegas (Falke).
} 


\title{
El existencialismo filosófico como praxis literaria
}

\begin{abstract}
Aurelio — dije- y si uno no puede llegar a tener una visión correcta de la existencia, una perspectiva verdadera, una visión realista del mundo a través de los estudios filosóficos. ¿Cómo podría llegar a tenerla? No hay modo - dijo Aurelio-. La filosofía no sirve para nada. Me equivoqué. Lo único que puede hacerse es vivir. Querer tener una visión realista del mundo es una pretensión tonta, eso no puede existir, existe una visión, mil visiones, pero no la correcta ni la incorrecta, existe la artificial, la que uno elucubra de espalda a la vida o a la naturaleza, o frente a ellas, pero olvidando que uno es parte de la vida y de la naturaleza (1985:345).
\end{abstract}

Luego de una conversación donde la filosofía queda como un juego de pensamiento que no dice nada acerca de la realidad ni el transitar por el mundo y sus paradojas, el protagonista sigue su vida dejándose llevar por el río. Uno pensaría que Aurelio también se deja llevar, pero éste se suicida, siendo coherente con sus pensamientos y con el pensamiento de Camus. El suicidio consternó al protagonista, quien finalmente se formula preguntas “complejas” como: “¿Qué hacer?” Y, luego de pensar varias opciones escoge: "la meningitis" como metáfora de un suicidio lento, inesperado, absurdo. De este modo, el existencialismo que marca toda la novela vuelve existencialista cada recorrido narrativo y, por supuesto, su culminación.

La meningitis, metafórica y seriamente, no sólo aparece como escogencia en La noche escuece. También está presente en El bonche cuando el protagonista escogió la piroplasmosis, otra forma de meningitis. Podemos elucubrar con el sentido de esta enfermedad a sabiendas de que las meninges, es decir, las membranas que cubren el cerebro y la médula espinal, se transforman en una metáfora de presión sobre nuestro pensar, sobre las diversas formas que tenemos de ver el mundo y aquello que nos acontece. El final que presenta Rodríguez busca la ruptura con el absoluto, la jaula hegeliana y evade sus primeras trampas: la muerte, el vacío, la incomunicación. El existencialista, en su praxis, sabe el valor de la escogencia, aunque ésta sea un error; aunque se escoja la enfermedad como una modulación, como una voz a la que se nos enseña a desdeñar; o se escoja el fallo, lo incoherente, pensamos que en la praxis existencialista el recurso a la meningitis es una forma de superar el suicidio, las trampas del discurso hegemónico, absoluto, y de mostrar las paradojas internas de una racionalidad sin grietas.

Desde el prefacio de la Fenomenología del espíritu (1986), Hegel nos habla del absoluto como de aquello que sólo es al final lo que es, y del conocimiento absoluto como mira de su filosofía que se realiza al final. Pero si el final es una meningitis, una piroplasmosis, obviamente no hay un fin, si vemos lo absoluto como una abolición entre el objeto y el sujeto de saber. Un sujeto al cual se opusiera un objeto distante de él o exterior a él no sería sujeto 


\section{Álvaro Martín Navarro}

absoluto; y un objeto al cual se agregase un sujeto que lo contempla o lo manipula no sería un objeto absoluto. Es preciso abolir, entonces, su distancia; esta abolición no es, claro está, la identificación inmediata del sujeto y del objeto, aún menos la unión mística aquí y ahora, como trató de instaurar Kierkegaard en La enfermedad mortal (2008), cuando invoca la oposición entre el existente singular — “yo” como individuo existente- y el punto de vista de Dios, es un proceso que transita con la historia pero no con el mundo. La historia vendría siendo un eje de dimensión "temporal" que permite la coexistencia de diferentes puntos de vista, pero cada uno de estos subsume hacia un saber absoluto que vendrá al final de los tiempos y que puede reanudar sin exceso ni defecto lo que se ha desarrollado en el tiempo. Pero en el tiempo del protagonista, al final está la pérdida, la imposibilidad de desarrollarse, de contactarse en el mundo en espacios, en bloques de recuerdos que se nutren y se transmutan. Estos elementos propios del existencialismo se alejan de su objeto de Saber, apuntan a la razón subjetiva, se fracturan, se dividen y no piden reconciliación. De aquí la metáfora de pensar el absurdo y escoger lo inverosímil como realidad, tal y como se presenta al final de las novelas de Rodríguez, o en el final de los escritos de $L a$ enfermedad mortal, donde Kierkegaard cuestiona la aceptación de lo divino, por más absurdo que se presente, como el Dios de Abraham en las reflexiones de Kierkegaard; o los finales de Sartre, donde en La náusea Antoine se pregunta sobre la importancia del libro y cómo lo leerá él posteriormente y si logrará identificarse con lo que escribió allí; o Camus quien termina La peste con las siguientes palabras

Rieux tenía presente que esta alegría está siempre amenazada. Pues él sabía que esta muchedumbre dichosa ignoraba lo que se puede leer en los libros, que el bacilo de la peste no muere ni desaparece jamás, que puede permanecer durante decenios dormido en los muebles, en la ropa, que espera pacientemente en las alcobas, en las bodegas, en las maletas, los pañuelos y los papeles, y que puede llegar un día en que la peste, para desgracia y enseñanza de los hombres, despierte a sus ratas y las mande a morir en una ciudad dichosa (1982:138).

En síntesis, los escritos existencialistas no pueden terminar en un Saber Absoluto. Se descubren finitos en la medida en que se piensa y se descubre que hay enfermedad, fractura, locura, pérdida, subjetividad, vértigo, por lo que una de las mayores polémicas sobre el existencialismo es que éste no logra una superación entre los contrarios; sólo muestra las distinciones y las paradojas y busca vivirlas en el lenguaje. Por otro lado, el discurso filosófico busca concretar la obra, implantar su carácter ensayístico — establecido en sus orígenes modernos por autores como Montaigne- y eliminar la duda, 
herencia moderna y cartesiana, que trató de mediar las diferencias. En el existencialismo contemporáneo que asoma en las obras literarias, se busca una visión de tránsito en el mundo; ya no se trata de mediar las diferencias, sino de aceptarlas, con rasgos de cinismo en la medida en que denotamos este saber y su imposibilidad para superarlo. Este enlace existencialista-cínico, quizás, marque un pensar filosófico contemporáneo que, sin embargo, ya se anunciaba en la literatura y, especialmente, en Latinoamérica. Se trata de un pensamiento más cercano y probable que el positivismo que aceptamos como guía para desarrollar, en estas tierras, el pensamiento académico. En fin, entramos en un siglo donde lo absoluto se ve más fragmentado y la existencia más ajena.

Si bien este ensayo se muestra como un anverso y un reverso de una moneda que es el existencialismo, su anverso, la postura filosófica no es incongruente con la praxis literaria que se muestra como reverso, si bien ésta puede tener lecturas más sociológicas, psicológicas o políticas que propiamente filosóficas. La praxis literaria desvela, precisamente, las rupturas con las grandes categorías que, de una u otra manera, la filosofía administraba hasta mediados del siglo XIX —incluyendo la literatura - y si bien parece que el existencialismo literario, dentro de la práctica ficcional es marcado por el discurso del existencialismo filosófico, en el fondo pensamos que son diversas modulaciones ante el mismo problema: el absoluto o ciertos anclajes de sentidos dados por una seguridad social, política, religiosa o económica. En otras palabras, las seguridades discursivas se textualizan en una escritura particular que desarrolla el autor con rizomas de juegos de lenguajes, tomando el eje del existencialista filosófico y planteando su posibilidad como praxis literaria, que pensamos desarrolla con gran maestría Renato Rodríguez. Su resultado es una escritura en que se enfrenta lo débil ante las estructuras de seguridad, mostrando, a la vez, una metamorfosis que radica en que la pérdida de sentido, que no es una estructura, se transforme en una estructura y auspicie una escritura cínica, con matices nihilistas, que tiende a encerrarse en paradojas que pensamos, marca una gran cantidad de escritos contemporáneos.

Kansai Gaidai University* Facultad de Lenguas Extranjeras Departamento de Español

D.P. 16-1 Nakamiyahigashino-cho, Hirakata City, Osaka 573-100 (Japón) navarroa@kansaigaidai.ac.jp 
Álvaro Martín Navarro

\section{BIBLIOGRAFÍA}

BAUDRILLARD, J. La transparencia del mal. Barcelona: Anagrama, 1993.

CAMUS, A. El mito de Sísifo. Barcelona: Alianza, 1995.

------ La peste. Buenos Aires: Losada, 1985.

CASTORIADIS, C. Sujeto y verdad en el mundo histórico social. México: F.C.E., 2004.

FOUCAULT, M. Entre Filosofía y literatura. Barcelona: Paidós, 1999. - Vigilar y castigar. México: F.C.E., 1991.

HEGEL., G. W. F. Fenomenología del espíritu. México: F.C.E., 1986.

KIERKEGAARD, S. La enfermedad mortal. Barcelona: Trotta, 2008.

------- O lo uno o lo otro. Fragmento de vida I. Barcelona: Trotta, 2007. Temor y temblor. Barcelona: Orbis, 1987.

------- El concepto de la angustia. Madrid: Espasa-Calpe, 1979.

PRINI, P. Historia del existencialismo. Buenos Aires: El Ateneo, 1975.

RODRÍGUEZ, R. Quanos. Caracas: Monte Ávila, 1996a.

------ Ínsulas. Caracas: FUNDARTE /Alcaldía de Caracas, 1996b.

------ El bonche. Caracas: Monte Ávila, 1976.

------ Al sur del equanil. Caracas: Monte Ávila, 1972.

------ La noche escuece. Caracas: Libros RARos, 1985.

------ ¡Viva la pasta! Caracas: Libros RARos, 1984.

SAFRANSKI, R. El mal o el drama de la libertad. Barcelona: Tusquets,2002.

SARTRE, J. P. La náusea. Barcelona: Alianza, 1988.

------ (s/f). El existencialismo es humanismo [en línea]. Disponible de http://www.uruguaypiensa.org.uy/imgnoticias/766.pdf [Visitado el 03/06/09].

SLOTERDIJK, P. Crítica de la razón cínica. Barcelona: Siruela, 2006.

VV.AA. Historia de la Ética. III Tomo. Comp. Victoria Camps. Barcelona: Crítica, 2002.

WITTGENSTEIN, L. Los cuadernos azul y marrón. Barcelona: Tecnos,1998. 